\title{
Studies on poly-3-hydroxyoctanoate biosynthesis by a consortium of microorganisms
}

\author{
Mihaela Carmen EREMIA ${ }^{1, *}$, Irina LUPESCU ${ }^{1,2}$, Mariana VLADU $^{1}$, Maria PETRESCU ${ }^{1}$, Gabriela SAVOIU ${ }^{1}$, \\ Amalia STEFANIU ${ }^{1}$, Maria SPIRIDON ${ }^{1}$ \\ ${ }^{I}$ National Institute for Chemical - Pharmaceutical Research and Development - Bucharest, 112 Vitan Av., \\ 031299, Bucharest, Romania \\ ${ }^{2}$ Spiru Haret University, Faculty of Veterinary Medicine, 030352, Bucharest, Romania
}

\begin{abstract}
Polyhydroxyalcanoates (PHAs) are specifically produced by a wide variety of bacteria, as an intracellular energy reserve in the form of homo- and copolymers of [R]- $\beta$-hydroxyalkanoic acids, depending on the $\mathrm{C}$ source used for microorganism growth, when the cells are grown under stressing conditions. In this paper we present microbiological accumulation of poly-3-hydroxyoctanoate (PHO) by using a consortium of bacterial strains, Pseudomonas putida and Bacillus subtilis, in a rate of 3:1, grown on a fermentation medium based on sodium octanoate as the sole carbon source. The experiments performed in the above mentioned conditions led to the following results: from $18.70 \mathrm{~g}$ sodium octanoate $(7.72 \mathrm{~g} / \mathrm{L}$ in the fermentation medium) used up during the bioprocess, 3.93-3.96 g/L dry bacterial biomass and 1.834 - $1.884 \mathrm{~g} / \mathrm{L}$ PHA, containing 85.83 - 86.8\% PHO, were obtained.
\end{abstract}

Keywords: polyhydroxyalcanoates, Pseudomonas putida, Bacillus subtilis, sodium octanoate, poly-3hydroxyoctanoate.

\section{Introduction}

Poly( $\beta$-hydroxyalkanoic acid)s (PHAs), also known as polyhydroxyalkanoates or microbial polyester, are a class of natural thermoplastic polymers [1]. Due to their properties, similar to those of conventional plastics and to their biodegradability, have attracted much interest as alternatives to synthetic polymers, the more so as they can be produced from renewable resources and processed with the aid of equipments used for polyolefins or other synthetic materials. The mechanical properties of PHAs depend on monomer structure and on molecular weight of polymers, varying between rubber like elasticity and brittleness of crystalline textolite.

Microbial polyhydroxyalkanoates comprise a wide variety of different polyesters, with more than 150 (R)-hydroxyalkanoates identified as known constituents, who are synthesized intracellularly as carbon and energy storage compounds under unbalanced growth conditions [2].

PHAs are biodegradable, biocompatible and naturally accumulated by several bacteria such as Alcaligenes, Pseudomonas, Bacillus, Rhodococcus, Cupriavidus and some species of photosynthetic bacteria under conditions of nutrient stress [3-9].

\footnotetext{
*Corresponding author: mihaelaceremia@yahoo.com
}

Numerous researchers have attempted to isolate PHA producing-microorganisms from various sources since the potential to discover and identify novel species with vastly superior production capacity remains untapped [10-13].

In this paper we present microbiological accumulation of poly-3-hydroxyoctanoate (PHO) by using a consortium of bacterial strains, Pseudomonas putida and Bacillus subtilis, in a rate of 3:1, grown on a fermentation medium based on sodium octanoate as the sole carbon source. The isolation process needs a pre-treatment and degreasing, followed by solvent extraction and purification. The resulted polymer was suspended in chloroform and evaporated until a thin pellicle was obtained.

\section{Experimental}

\subsection{Materials}

Components of nutritive media were purchased from Merck and Sigma-Aldrich, organic solvents, analytical reagents and mineral salts, from Merck, except for methyl esters of 3-hydroxy acids (C8, C9, C10), purity $98 \%$ purchased from Larodan, Sweden.

The PHA producing microorganisms were three laboratory strains (wild type), Pseudomonas putida ICCF 391, Bacillus subtilis BSP ICCF 84 and Bacillus subtilis BSV ICCF 349, and their 
performances are presented as experiments 1,2 and 3. Stock cultures were grown at $28^{\circ} \mathrm{C}$ and maintained by periodic transfer on M44 (cDSMZ424) agar slants.

\subsection{Procedures and methods}

\section{Inoculum growth medium and cultivation} conditions

A microbial suspension in sterile distilled water was prepared from the stock culture. $10 \mathrm{~mL}$ of a medium containing $(\% \mathrm{~g} / \mathrm{v})$ : glucose $1 \%$, corn extract $1.5 \%, \mathrm{KH}_{2} \mathrm{PO}_{4} 1 \%, \mathrm{NaCl} 1 \%, \mathrm{MgSO}_{4} \quad 0.05 \%$ previously sterilized at $115^{\circ} \mathrm{C}$, for 20 minutes was inoculated with $1 \mathrm{~mL}$ of the above-mentioned microbial suspension, containing $10^{7} \mathrm{cfu} / \mathrm{mL}$. The inoculum (preculture) was prepared in $500 \mathrm{~mL}$ Erlenmeyer flasks, by incubation at $30^{\circ} \mathrm{C}$, for $20-24$ hours, on a laboratory rotary shaker (Heidolph Germany) at $220 \mathrm{rpm}$.

\section{Fermentation conditions}

Batch fermentations were performed in $750 \mathrm{~mL}$ Erlenmeyer flasks, containing $250 \mathrm{~mL}$ of fermentation medium. Bioprocess medium had the following composition in mineral salts (medium $\mathrm{E}$ ): $\mathrm{NaNH}_{4} \mathrm{HPO}_{4} \cdot 4 \mathrm{H}_{2} \mathrm{O} \quad 0.35 \mathrm{~g} \%, \mathrm{~K}_{2} \mathrm{HPO}_{4} 0.75 \mathrm{~g} \%$, $\mathrm{KH}_{2} \mathrm{PO}_{4} 0.37 \mathrm{~g} \%$, trace element solution I $0.1 \mathrm{~mL} \%$, trace element solution II $0.1 \mathrm{~mL} \%$. Trace element solution I contains $120 \mathrm{~g} / \mathrm{L} \mathrm{MgSO} \cdot 7 \mathrm{H}_{2} \mathrm{O}$. Trace element solution II contains per liter, $2.78 \mathrm{~g}$ of $\mathrm{FeSO}_{4} \cdot 7 \mathrm{H}_{2} \mathrm{O}, 1.47 \mathrm{~g}$ of $\mathrm{CaCl}_{2} \cdot 2 \mathrm{H}_{2} \mathrm{O}, 1.98 \mathrm{~g}$ of $\mathrm{MnCl}_{2} \cdot 4 \mathrm{H}_{2} \mathrm{O}, 2.81 \mathrm{~g}$ of $\mathrm{CoSO}_{4} \cdot 7 \mathrm{H}_{2} \mathrm{O}, 0.17 \mathrm{~g}$ of $\mathrm{CuCl}_{2} \cdot 2 \mathrm{H}_{2} \mathrm{O}$, and $0.29 \mathrm{~g}$ of $\mathrm{ZnSO}_{4} \cdot 7 \mathrm{H}_{2} \mathrm{O}$ in $1 \mathrm{M} \mathrm{HCl}$. The sterilized fermentation medium (as mentioned above) was inoculated with $10 \%$ (v/v) preculture and incubated at $30^{\circ} \mathrm{C}$, for 48 hours, on a rotary shaker, at $220 \mathrm{rpm}$. At 0 and 24 hours of cultivation, the medium was supplemented with octanoic acid, to a final concentration of $0.425 \% \mathrm{~g} / \mathrm{v}$, according to the HPLC assay of octanoic acid content, and other several measurements were carried out: $\mathrm{pH}$, dry cells and optical density (OD) to measure the bacterial growth, and mcl-PHA content, measured by GC-FID

Biomass separation and preparation postbiosynthesis

At the end of the fermentation process particles of bacterial cells were separated by centrifugation at $4000 \mathrm{rpm}$, in a centrifuge (Hettich - Germany), washed with water and methanol and the obtained suspension was centrifuged again, in the same conditions.

For this experimental recovery procedure, a preliminary methanol treatment of dried bacterial biomass was performed, in order to dissolve certain non PHAs components, susceptible to be further extracted in acetone. Methanol was added to the dried biomass at a ratio of $20: 1 \quad(\mathrm{v} / \mathrm{g})$; the resulted suspension was stirred 30 minutes at room temperature, and then centrifuged, and the sediment washed with distilled water and vacuum dried. Soxhlet extraction with acetone was conducted at 55$57^{\circ} \mathrm{C}$, during 5 hours. The PHA containing acetone solution was filtered (for removing bacterial cell components carried by acetone vapors) and concentrated at $2 / 3$ from the initial volume. Methanol was added to the concentrated acetone and PHAs precipitated as a clay, which was dissolved in chloroform. PHA chloroform solution was evaporated slowly at room temperature to form a polymer film.

\section{PHA assay}

The gas chromatographic method used for the determination of the polymers obtained by laboratory fermentations with the three bacterial strains above mentioned consisted of a mild acid methanolysis of the polymers followed by gas chromatography of the resulted methyl ester mixture [14]. The polymer composition and purity degree resulted by summing all of the contained monomers, determined by GCFID, and expressed in $\mathrm{g} / 100 \mathrm{~g}$ product or in $\%$ moles. For the monomer composition determination, a capillary column has been used with a HP 5 (5\% phenyl - methylpolysiloxan) stationary PHAs. Methyl esters of C6 - C 10 hydroxy acids have been used as standard substances.

\section{Results and Discussions}

\subsection{PHAs bacterial biosynthesis}

Several experiments were performed going through all specific stages of a microbial biosynthesis process. We tested two consortia of microorganisms, $P$. putida and B. subtilis / B. subtilis BSV in a ratio of 3:1, compared to PHA biosynthesis with $P$. putida.

Evolution of the fermentation process was followed by measurements of $\mathrm{pH}$, optical density, dry cell weight and consumption of $\mathrm{C} 8$ during fermentation (HPLC), as shown in Table 1.

Table 1. Fermentations in system fed batch for PHA biosynthesis

\begin{tabular}{|c|c|c|c|c|c|}
\hline \multirow{2}{*}{ No. } & \multirow{2}{*}{ Strains } & \multirow{2}{*}{$\begin{array}{c}\mathrm{C} 8 \\
(\mathrm{~g} / \mathrm{L})\end{array}$} & \multicolumn{3}{|c|}{ Fermentation evolution } \\
\hline & & & $\mathrm{pH}$ & $\mathrm{OD}^{1}$ & $\begin{array}{l}\mathrm{DC}^{2} \\
(\mathrm{~g} / \mathrm{L})\end{array}$ \\
\hline 1 & P.putida & 8.51 & 7.74 & 0.559 & 1.86 \\
\hline 2 & $\begin{array}{l}\text { P.putida: } \\
\text { B.subtilis } \\
\text { BSP (3:1) }\end{array}$ & 8.51 & 7.55 & 0.599 & 3.96 \\
\hline 3 & $\begin{array}{l}\text { P.putida: } \\
\text { B.subtilis } \\
\text { BSV (3:1) }\end{array}$ & 8.51 & 7.60 & 0.562 & 3.93 \\
\hline
\end{tabular}

\footnotetext{
${ }^{1}$ Optical Density measured at $550 \mathrm{~nm}$

${ }^{2}$ Dry Cell Weight /L
} 
Correlating data from the experiments carried out, we observed that using a sole microorganism $(P$. Putida), a smaller amount of dry biomass $(\mathrm{g} / \mathrm{L})$ was obtained, comparing with the fermentation of the microorganism consortium.

From all the precursor amount (octanoate) used up by the consortium during the fermentation, 18.72 $\mathrm{g}(8.51 \mathrm{~g} / \mathrm{L}$ in the fermentation medium), $3.93-3.96$ $\mathrm{g} / \mathrm{L}$ dry bacterial biomass and 1.834 - $1.884 \mathrm{~g} / \mathrm{L}$ PHA, containing 85.83 - 86.8\% PHO were obtained (Fig. $1)$.

\subsection{PHA extraction}

For Soxhlet acetone extraction of PHA, dry biomass was used after a methanol treatment for removing impurities susceptible to be extracted in acetone. The isolation-purification yields varied between 44 and $50 \%$ depending on the polymer content of dry cells.

The composition and purity of polymers isolated by Soxhlet extraction with acetone were determined by GC-FID and expressed in g/100 g product analyzed or mole\% (Table 2).

Table 2. Analytical characteristics of polymers biosynthesized

\begin{tabular}{cccccc}
\hline & & \multicolumn{4}{c}{ Hydroxy acids } \\
\cline { 3 - 6 } $\begin{array}{c}\text { No.* } \\
\text { Experiment }\end{array}$ & \begin{tabular}{c} 
PHA \\
\cline { 3 - 6 }
\end{tabular} & $\begin{array}{c}\text { C6 } \\
(\%)\end{array}$ & $\begin{array}{c}\text { C8 } \\
(\%)\end{array}$ & $\begin{array}{c}\text { C10 } \\
(\%)\end{array}$ & $\begin{array}{c}\text { Molar ratio } \\
\text { C6:C8:C10 }\end{array}$ \\
\hline 1 & 47.6 & 5.38 & 85.83 & 6.45 & $3.75: 50: 3.2$ \\
2 & 44.0 & 5.52 & 86.80 & 5.65 & $3.8: 50: 5.7$ \\
3 & 47.5 & 5.55 & 86.56 & 5.68 & $3.8: 50: 2.9$ \\
\hline
\end{tabular}

*The polymers presented are obtained from the fermentation above mentioned in experiments No. 1, 2 and 3.

The analytical results show that in the conditions experimentally established for isolation and purification of PHAs obtained using octanoate as a precursor fed every six hours, polymers with content in $\mathrm{C} 8$ ranging between 85.83 to $86.8 \%$, C6 between 5.38 and $5.55 \%$ and $\mathrm{C} 10$ between 5.65 and $6.45 \%$ are obtained.

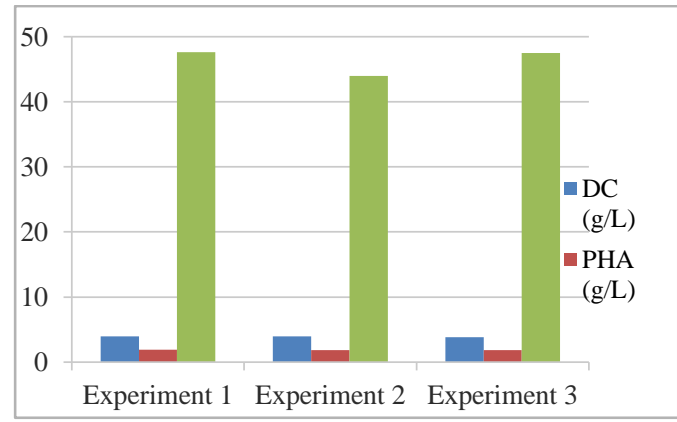

Figure 1. Biomass and mcl-PHA production with consortium of microorganisms
A PHO film obtained in conditions above mentioned is showed in Fig. 2.

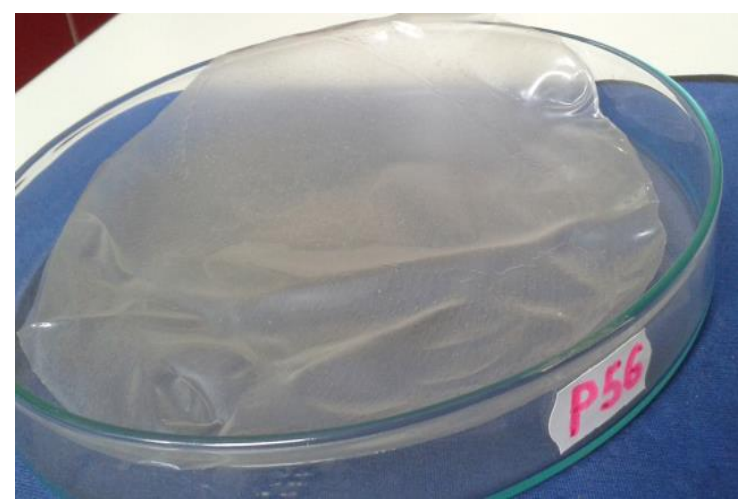

Figure 2. Examples of polymers biosynthesized from Ps. Putida and B. Subtilis containing the PHO / PHA between $85.83-86.8 \%$

\section{Conclusions}

The experiments carried out in this work were focused on the use of the consortium formed of one strain of Ps. putida and two strains of B. subtilis selected as PHA producers, due to their ability to use octanoic acid as unique sources of $\mathrm{C}$ and energy for cell growth.

The results revealed the consortium performances to produce mcl-PHA by conversion of $\mathrm{C} 8$ at a maximum limit of $18.87 \mathrm{~g}$ octanoic acid.

Thus, polymers containing (in percentages) 5.385.55 C 6, from 85.83 to $86.8 \mathrm{C} 8$, and 5.65 to $6.45 \mathrm{C} 10$ were obtained.

Acknowledgments. This research was supported by PNCDI Grant "Innovative Polyester/Bacterial Cellulose Composites for Biomedical Engineering", supported by the National Centre for Programs Management (CNMP).

\section{References}

[1] M.B. Kellerhals, B. Kessler, B. Witholt, Development of a closed-loop control system for production of medium-chain-length poly(3hydroxyalkanoates) (mcl-PHAs) from bacteria. Macromolecular Symposia 144, 385-9 (1999).

[2] A. Steinbüchel, H.E. Valentin, Diversity of bacterial polyhydroxyalkanoic acids. FEMS Microbiol. Lett. 128, 219-228 (1995).

[3] D. Jendrossek, Microbial degradation of polyesters. Adv. Biochem.Eng. Biotechnol. 71, 293-325 (2001).

[4] D.Y. Kim, Y.H. Rhee, Biodegradation of microbial and synthetic polyesters by fungi. Appl. Microbiol. Biotechnol. 61, 300-308 (2003).

[5] G. Q. He, Q. Kong, L. X. Ding, Response surface methodology for optimization the 
fermentation medium of Clostridium butyricum., Lett. Appl. Microbiol. 39, 363-368 (2004).

[6] N. Jamil, N. Ahmedand, D. H. Edwards, Characterization of biopolymer produced by Pseudomonas sp. CMG607w of marine origin, J. Gen. Appl. Microbiol. 53, 105-109 (2007).

[7] L. L. Madison, G. W. Huisman, Metabolic engineering of poly(3-hydroxyalkanoates): From DNA to plastic. Microbiol. Mol. Biol. Rev. 63, 21-53 (1999).

[8] A. Shrivastav, S.K Mishra, B. Shethia, I. Pancha, D. Jain, S. Mishra, Isolation of promising bacterial strains from soil and marine environment for polyhydroxyalkanoates (PHAs) production utilizing Jatropha biodiesel byproduct, Int. J. Biol. Macromol. 47, 283-287 (2010).

[9] K. Tajima, T. Igari, D. Nishimura, M. Nakamura, Y. Satoh, M. Munekata, Isolation and characterization of Bacillus sp. INT 005 accumulating polyhydroxyalkanoate (PHA) from gas field soil, J. Biosci. Bioeng. 95, 77- 81 (2003).

[10] X. Liu, P.X. Ma, Polymeric Scaffolds for Bone Tissue Engineering, Annals of Biomedical Engineering 32, 477-86 (2004).
[11] V.P. Cyras, N.G. Fernández, A. Vázquez, Biodegradable films from $\mathrm{PHB}-8 \mathrm{HV}$ copolymers and polyalcohols blends: crystallinity, dynamic mechanical analysis and tensile properties, Polymer International 48, 705-12 (1999).

[12] L.S. Nair, C.T. Laurencin, Biodegradable polymers as biomaterials, Progress in Polymer Science 32, 762-98 (2007).

[13] T. Pompe, K. Keller, G. Mothes, M. Nitschke, M. Teese, R. Zimmermann, C. Werner, Surface modification of poly(hydroxybutyrate) films to control cell-matrix adhesion, Biomaterials $\mathbf{2 8}$, 28-37 (2007).

[14] M. Koller, P. Hesse, R. Bona, C. Kutschera, A. Atlic, G. Braunegg, Biosynthesis of High Quality Polyhydroxyalkanoate Co- and Terpolyesters for Potential Medical Application, Macromol. Symp. 253, 33-39 (2007).

Received: 19.04 .2016

Received in revised form: 31.05 .2016

Accepted: 02.06.2016 